\title{
Clínica em saúde bucal como espaço de produçãa de diálogo, vínculo e subjetividades entre usuários e cirurgióes-dentistas da Atenção Primária à Saúde ${ }^{1}$
}

| ${ }^{1}$ Vinícius Antério Graff, ${ }^{2}$ Ramona Fernanda Ceriotti Toassi I

Resumo: Pesquisa qualitativa de base fenomenológica (estudo de caso) cujo objetivo foi analisar os sentidos atribuídos às práticas clínicas por cirurgiôes-dentistas da Atenção Primária à Saúde (APS) na produção do cuidado. Entrevistas semiestruturadas guiadas por um roteiro de questôes norteadoras com cirurgióes-dentistas que atuavam em serviços de APS e a observação não estruturada da rotina clínica desses profissionais com registros em diário de campo foram utilizadas para a coleta de dados. A amostra foi intencional, seguindo o critério da saturação teórica e da densidade do material textual produzido $(\mathrm{n}=11)$. Os resultados mostraram cirurgióes-dentistas com práticas clínicas capazes de produzir subjetividades e vínculo, caracterizadas por um acolhimento de escuta e diálogo com o usuário e pela pactuação de um plano terapêutico compartilhado e em constante reconstrução, contrária a uma assistência com foco dentário voltada a necessidades diagnosticadas exclusivamente pelo profissional. O usuário foi reconhecido como um sujeito de experimentação e interação social, cujas necessidades do corpo vivido vão além das de um corpo físico. Propostas de inovação pedagógica nos currículos da área da saúde devem trazer bases teóricas e atividades práticas que incluam as subjetividades como uma das dimensóes do modo de produção do cuidado em saúde e as tecnologias relacionais.

> Palavras-chave: integralidade; saúde bucal; pesquisa qualitativa; Atenção Primária à Saúde; Sistema Único de Saúde.

\author{
${ }^{1}$ A pesquisa apresentada no \\ artigo é resultado de dissertação \\ de mestrado do Programa de Pós- \\ graduação em Ensino na Saúde \\ (PPGEnSau) da Universidade \\ Federal do Rio Grande do Sul \\ (UFRGS). \\ ${ }^{2}$ Grupo Hospitalar Conceição. \\ Porto Alegre-RS, Brasil \\ (graffvinicius@gmail.com). \\ ORCID: 0000-0002-1021-8535. \\ 3 Programa de Pós-graduação em \\ Ensino na Saúde da Faculdade \\ de Medicina, Universidade \\ Federal do Rio Grande do Sul. \\ Porto Alegre-RS, Brasil (ramona. \\ fernanda@ufrgs.br). \\ ORCID: 0000-0003-4653-5732.
}

Recebido em: 30/06/2017 Revisado em: 25/04/2018 Aprovado em: 22/06/2018 


\section{Introdução}

Políticas de saúde e educação promoveram avanços na reorientação de práticas de atenção à saúde no Brasil. Na saúde bucal, a incorporação e expansão da Estratégia de Saúde da Família (ESF) com a inclusão da equipe de saúde bucal, a partir de 2000, viabilizou que cuidados de saúde bucal integrassem as açôes da Atenção Primária à Saúde (NASCIMENTO et al., 2013). Em 2004, a implantação da Política Nacional de Saúde Bucal - "Brasil Sorridente" - tornou a saúde bucal uma das quatro áreas prioritárias do Sistema Único de Saúde (SUS), transformando a saúde bucal no Brasil (BRASIL, 2004a; PUCCA JÚNIOR et al., 2015). Houve avanços em relação ao financiamento para equipes de saúde bucal na ESF e na implantação de serviços e procedimentos de média e alta complexidade, caracterizando uma rede articulada de cuidado em diferentes níveis de atenção à saúde (PUCCA JÚNIOR et al., 2009). Alia-se ao contexto, a implementação da Política Nacional de Humanização (PNH), com a valorização das dimensões subjetivas e sociais em todas as práticas no SUS (BRASIL, 2004b).

Estabeleceu-se, assim, uma nova perspectiva para a consolidação do conceito de integralidade do cuidado promovido pela ampliação e qualificação do escopo de ações em saúde bucal, com impacto tanto nas açôes de promoção, proteção, recuperação e reabilitação da saúde quanto nos processos de trabalho nos serviços públicos (BARTOLE, 2008; SANTOS, 2006). Tem-se uma prática mais integral, porém, com ecos menores no que se refere à produção de tecnologias de cuidado em ambiente clínico (BARROS; BOTAZZO, 2011).

Já na educação, as Diretrizes Curriculares Nacionais, impulsionadas por iniciativas como o Programa Nacional de Reorientação da Formação Profissional em Saúde - PRÓ-SAÚDE, o Programa de Educação pelo Trabalho para a Saúde PET-Saúde e, mais recentemente, o PET-Saúde GraduaSUS, induziram a elaboração e o desenvolvimento de projetos pedagógicos diferenciados nos cursos de graduação em saúde, com currículos integrados de base interdisciplinar e articulados ao SUS (BRASIL, 2002; BRASIL, 2007a; BRASIL, 2010; BRASIL, 2015). Destacamse, ainda, estratégias importantes para promover a aproximação entre educação e trabalho, como as residências multiprofissionais em saúde (BRASIL, 2005).

A odontologia acompanhou esse movimento e a formação de cirurgiōes-dentistas no país tem sido reorganizada no sentido de promover um perfil de profissionais 
egressos aptos a atuar no SUS (WARMLING et al., 2011). Apesar dos inegáveis e reconhecidos avanços, a reformulação de saberes e práticas para reorientar a clínica odontológica não teve, entretanto, as modificações esperadas e necessárias.

Para alcançar a integralidade do cuidado, a clínica deve ser "ampliada" no sentido de possibilitar que outros aspectos do sujeito, que não apenas o físico, possam e devam ser compreendidos pelos profissionais. Para tanto, esses profissionais devem estar capacitados para identificar as necessidades percebidas e as não percebidas pelos indivíduos (CAMPOS, 1999; CUNHA, 2010; BRASIL, 2007b).

O encontro terapêutico entre usuário e profissional prevê uma relação de interesse e empatia, de interação de pessoas buscando o alívio de um sofrimento ou o alcance de um bem-estar (VILELA et al., 2014; AYRES, 2004). Trata-se de uma relação mediada pela utilização de tecnologias leves de cuidado, ou seja, tecnologias envolvidas no processo das relaçôes, estabelecidas a partir de um trabalho vivo, com interlocução, possibilitando falas, escutas e interpretações (MERHY; FRANCO, 2003).

Entendendo a importância da qualidade da relação estabelecida entre usuário e profissional para as ações de atenção à saúde, o presente estudo teve como objetivo analisar os sentidos atribuídos às práticas clínicas por cirurgiôes-dentistas da Atenção Primária à Saúde (APS) na produção do cuidado.

\section{Percurso metodológico}

Trata-se de um estudo de caso de abordagem qualitativa, cujo campo de investigação foram as Unidades de Atenção Primária à Saúde do Serviço de Saúde Comunitária do Grupo Hospitalar Conceição (SSC/GHC), em Porto Alegre, Rio Grande do Sul.

O Grupo Hospitalar Conceição é referência para o SUS no campo da assistência, pesquisa e formação em saúde e no desenvolvimento de tecnologias em saúde. Sua estrutura envolve quatro hospitais, uma Unidade de Pronto Atendimento, o Serviço de Saúde Comunitária (SSC) e o Centro de Educação Tecnológica e Pesquisa em Saúde. O SSC é composto por 12 Unidades de Saúde localizadas na zona norte de Porto Alegre. Integram esse serviço 39 equipes de Saúde da Família constituídas pela equipe básica preconizada, além de assistentes sociais e psicólogos. Os núcleos de farmácia, nutrição, terapia ocupacional e psiquiatria também estão presentes, atuando na lógica de apoio matricial dos Núcleos de Apoio à Saúde da Família (NASF). O 
Serviço conta, também, com três Centros de Atenção Psicossocial (CAPS), além de uma equipe do Consultório na Rua. É campo de formação em APS para estágios curriculares de cursos da graduação em saúde e para os Programas de Residência Médica em Medicina de Família e Comunidade e Residência Multiprofissional ${ }^{1}$ em Saúde (GRUPO HOSPITALAR CONCEIÇÃO, 2017).

Foram convidados a participar da pesquisa os cirurgióes-dentistas trabalhadores das 12 Unidades de Saúde do SSC/GHC. Os profissionais deveriam estar atuando nas equipes de saúde bucal dessas Unidades de Saúde, desenvolvendo atividades clínicas e coletivas de promoção, prevenção e reabilitação da saúde bucal. Foram excluídos os cirurgiōes-dentistas que estavam afastados do trabalho (licença saúde/ licença maternidade/ licença interesse/ férias) ou que exercessem funções exclusivamente administrativas no período de realização do estudo.

A pesquisa foi aprovada pelos Comitês de Ética em Pesquisa da Universidade Federal do Rio Grande do Sul (CAAE 51239115.5.0000.5347) e do Grupo Hospitalar Conceição (CAAE 51239115.5.3001.5530). Entrevistas semiestruturadas individuais com os cirurgiôes-dentistas e a observação não estruturada com registros em diário de campo foram utilizadas para a produção dos dados.

As entrevistas foram gravadas por equipamento de áudio e transcritas na íntegra. Cada entrevista teve um tempo de duração de cerca de uma hora, seguindo um roteiro previamente testado, com 11 questôes norteadoras (Quadro 1). Todas as transcriçôes foram devolvidas aos entrevistados para que pudessem lê-las, verificando se estavam de acordo com as ideias apresentadas e, se julgassem necessário, modificassem e/ou complementassem seus depoimentos.

Quadiro 1. Questôes norteadoras do roteiro da entrevista.

\begin{tabular}{|l|l|}
\hline $\begin{array}{l}\text { QUESTÕES } \\
\text { NORTEADORAS }\end{array}$ & INFORMAÇÕES \\
\hline Perfil demográfico & Sexo, idade \\
\hline $\begin{array}{l}\text { Aspectos relacionados à } \\
\text { formação }\end{array}$ & $\begin{array}{l}\text { Tempo de conclusão da graduação } \\
\text { Curso de pós-graduação }\end{array}$ \\
\hline $\begin{array}{l}\text { Aspectos relacionados ao } \\
\text { trabalho }\end{array}$ & Tempo de trabalho na instituição \\
\hline
\end{tabular}

continua... 


\begin{tabular}{|l|l|}
\hline $\begin{array}{l}\text { QUESTÓES } \\
\text { NORTEADORAS }\end{array}$ & INFORMAÇÕES \\
\hline $\begin{array}{l}\text { Práticas clínicas de cuidado } \\
\text { em saúde na APS }\end{array}$ & $\begin{array}{l}\text { Descrição da rotina de atendimentos clínicos e } \\
\text { caracterização da abordagem ao usuário } \\
\text { Utilização do prontuário de família e ficha odontológica } \\
\text { Estabelecimento do plano terapêutico } \\
\text { Conceito de cuidado integral e clínica ampliada } \\
\text { Estabelecimento do vínculo entre usuário e cirurgião-dentista } \\
\text { Características do cirurgião-dentista para promover cuidado } \\
\text { em saúde } \\
\text { Relaçáo da prática de cuidado com a formação na graduação } \\
\text { Atuação como preceptor de estágio curricular da graduação } \\
\text { e residência }\end{array}$ \\
\hline
\end{tabular}

A observação foi realizada nas Unidades de Saúde de atuação dos entrevistados. A intençáo foi a de observar a rotina clínica desses profissionais, incluindo fatos concretos, relações interpessoais, experiências pessoais do investigador, conversas informais, reflexões e sentimentos durante o período da pesquisa.

Para o encerramento da coleta de dados, a qualidade do material textual obtido foi avaliada pelos pesquisadores, tanto em relação às repetições de temáticas e ideias apresentadas - saturação teórica (FONTANELLA et al., 2011) -, quanto em relação à densidade de conteúdo das entrevistas. Dos 25 cirurgiôes-dentistas trabalhadores das Unidades de Saúde do SSC, 11 foram entrevistados.

Para análise dos dados, foi utilizada a técnica da análise temática de conteúdo (BARDIN, 2011), com o auxílio do software Visual Qualitative Data Analysis (ATLAS.ti). A abordagem teórica usada foi a da fenomenologia enquanto estudo da significação e das essências (MERLEAU-PONTY, 2006), à luz dos conceitos de tecnologias leves do cuidado em saúde, clínica ampliada, abordagem centrada na pessoa e das Políticas Nacionais de Atenção Básica, Saúde Bucal e Humanização.

\section{Resultados e discussão}

Este é um estudo que trata de percepçôes. Entendendo que toda percepção se dá dentro de um ponto de vista específico, de um sujeito pensante situado em um ponto no mundo do tempo e do espaço, conhecer aspectos relacionados ao trabalho 
e formação dos cirurgiōes-dentistas entrevistados integra o processo de compreensão de suas percepçóes (MATTHEWS, 2011).

Dos 11 cirurgiôes-dentistas entrevistados, oito eram mulheres, com idade entre 32 e 56 anos. O tempo desde a conclusão da graduação variou de 9 a 33 anos, sendo que quatro entrevistados estavam formados há mais de 25 anos. Todos os profissionais realizaram cursos de Especialização e/ou Residência e sete apresentavam formação em diferentes modalidades de pós-graduação (Tabela 1). As especializações e/ou residências realizadas eram nas áreas de Saúde Pública/ Saúde Coletiva/ Saúde da Família e Comunidade e Informação em Saúde.

Tabela 1. Perfil demográfico, de trabalho e de formação dos cirurgióes-dentistas da APS.

\begin{tabular}{ll}
\hline VARIÁVEIS & $\mathrm{n}$ \\
\hline SEXO & 8 \\
\hline Feminino & 3 \\
\hline Masculino & 5 \\
\hline IDADE (ANOS) & 2 \\
\hline $32-35$ & 4 \\
\hline $36-40$ & \\
\hline 52-56 & 6 \\
\hline TEMPO DE CONCLUSÁO DA GRADUAÇÁO (ANOS) & 2 \\
\hline De 9 a 12 & 3 \\
\hline De 30 a 33 & 3 \\
\hline TEMPO DE TRABALHO NA INSTITUIÇÃO (ANOS) & 5 \\
\hline De 1 a 5 & 3 \\
\hline De 8 a 10 & 4 \\
\hline De 23 a 28 & 4 \\
\hline CURSOS DE PÓS-GRADUAÇÃO & 3 \\
\hline Especializaçáo e/ou Residência & 11 \\
\hline Especializaçáo e/ou Residência e Mestrado & \\
\hline Especializaçáo e/ou Residência, Mestrado e Doutorado & \\
\hline TOTAL & \\
\hline
\end{tabular}


O conjunto do material produzido pelas entrevistas e observação está apresentado em três categorias emergentes (Quadro 2).

Quadro 2. Categorias de análise

\begin{tabular}{|l|l|l|}
\hline Categorias de análise & Definição constitutiva & Definição operacional \\
\hline $\begin{array}{l}\text { Construção de sentidos na } \\
\text { clínica odontológica: rotinas } \\
\text { de encontros marcados pela } \\
\text { escuta, diálogos e produçáo } \\
\text { de subjetividades. }\end{array}$ & $\begin{array}{l}\text { Caracteriza as rotinas } \\
\text { de cuidado durante os } \\
\text { atendimentos clínicos dos } \\
\text { dentistas da APS. }\end{array}$ & $\begin{array}{l}\text { Operacionalizada por meio } \\
\text { dos seguintes aspectos: } \\
\text { - experiências e trajetórias } \\
\text { individuais no processo de } \\
\text { trabalho nos atendimentos } \\
\text { clínicos na APS. }\end{array}$ \\
\hline $\begin{array}{l}\text { O vínculo usuário- } \\
\text { profissional como estratégia } \\
\text { de práticas resolutivas do } \\
\text { cuidado em saúde. }\end{array}$ & $\begin{array}{l}\text { Expressa a compreensão } \\
\text { de como ocorre a } \\
\text { formação do vínculo entre } \\
\text { usuário e profissional, } \\
\text { enquanto um fenômeno } \\
\text { desejável para o processo } \\
\text { de trabalho em APS. }\end{array}$ & $\begin{array}{l}\text { Operacionalizada por meio } \\
\text { dos seguintes aspectos: } \\
\text { - características percebidas } \\
\text { pelos cirurgióes-dentistas } \\
\text { na constituiçáo do vínculo } \\
\text { usuário-profissional. }\end{array}$ \\
\hline $\begin{array}{l}\text { A constituição do cirurgião- } \\
\text { dentista em ato. }\end{array}$ & $\begin{array}{l}\text { Expressa as experiências de } \\
\text { constituição do profissional } \\
\text { da APS como cirurgião- } \\
\text { dentista. }\end{array}$ & $\begin{array}{l}\text { Operacionalizada por meio } \\
\text { dos seguintes aspectos: } \\
\text { - formaçáo na graduaçáo, } \\
\text { pós-graduação, prática } \\
\text { profissional como preceptor, } \\
\text { educação permanente. }\end{array}$ \\
\hline
\end{tabular}

\section{Construção de sentidos na clínica odontológica: rotinas de encontros marcados pela escuta, diálogos e produção de subjetividades}

As narrativas produzidas pelos cirurgiôes-dentistas entrevistados acerca das rotinas do cuidado, durante os atendimentos odontológicos realizados na APS, trouxeram, em um primeiro momento, aspectos voltados ao acolhimento do usuário.

O acolhimento é entendido como postura, atitude e tecnologia de cuidado (BRASIL, 2013). Segundo Merhy (1997; 2007), o acolhimento é uma tecnologia leve que acontece em ato, a partir do encontro que se estabelece entre trabalhadores e usuários, onde ocorrem diálogos, interpretaçôes e interesse pela vida do usuário. 
A abordagem inicial ao usuário expressou a preocupação do profissional em apresentar-se para que a pessoa saiba quem irá atendê-la e em chamá-la pelo seu nome, em detrimento da despersonificação, quando a identificação acontece como um "número" ou uma "ficha” nos serviços de saúde.

Vou até a sala de espera, chamo a pessoa pelo nome, cumprimento ele e me identifico, para as pessoas que eu não conheço (E2).

Reconhecido como um direito do usuário, táo importante quanto a identificação da pessoa pelo nome é a apresentação do profissional que estará cuidando dela (CANALLI et al., 2012; MATOS et al., 2016). A própria PNH reforça como uma prioridade para o usuário do SUS saber quem são os profissionais que cuidam de sua saúde (BRASIL, 2004b).

Um segundo momento desse acolhimento, percebido pelos cirurgióes-dentistas, diz respeito à escuta ao usuário, à atenção em relação ao que diz, e pelo diálogo entre o usuário e o profissional que busca conhecer a pessoa e suas necessidades.

[...] ouvir o que o traz, o que o motivou, o que veio buscar, qual a queixa, o que espera do serviço (E4).

O diálogo na prática clínica odontológica tem se caracterizado como um ato mecanizado e destituído do real desejo de ouvir atentamente o que a pessoa que procura cuidados tem a dizer (CANALLI et al., 2012). A ênfase está na técnica operatória, ou seja, no procedimento, nas etapas, no material, sem a preocupação com as tecnologias das relaçóes (MERHY, 1997). Se há uma intencionalidade do profissional em promover um cuidado efetivo em saúde, os aspectos subjetivos que envolvam o saber construído no cotidiano de vida das pessoas devem ser considerados. O diálogo não pode se reduzir à descrição de uma técnica operatória cujo foco tenha um centramento dentário (BOTAZZO, 2006; 2008).

Nessa perspectiva de busca pelo diálogo qualificado e resolutivo, emergiu das entrevistas um dispositivo de cuidado na saúde bucal caracterizado pela realização de um momento inicial de atendimento fora da cadeira odontológica e a utilização de outros espaços, que náo o "consultório do dentista", para a escuta ao usuário.

[...] tanto na primeira consulta quanto nas subsequentes, eu procuro fazer a conversa inicial, fora da cadeira odontológica, temos uma mesa de trabalho em que sentamos numa disposição de forma que possamos ficar um de frente para o outro, sem ter a mesa interposta; a parte de anamnese inicial e histórico do paciente eu procuro fazer de uma forma bem informal, para que eu possa já colher informações que possam ir além do roteiro da ficha clínica (E2). 
Botazzo et al. (2015) entendem que a consulta em saúde bucal realizada fora do ambiente "odontológico" é uma experiência de inovação e ampliação do cuidado na clínica de saúde bucal, uma vez que não se utiliza do "odontograma" para o registro do histórico de doenças e das necessidades de tratamento. É uma consulta que se baseia na história patográfica do usuário (SOUZA, 2003). Unemse, assim, dimensôes da história clínica e aspectos da história de vida dos usuários (KOVALESKI et al., 2010), o que tem potencial para eliminar parte da ansiedade gerada em relação à consulta, contribuindo para o sucesso dos resultados esperados (BARROS; BOTAZZO, 2011; CANALLI et al., 2012).

É preciso considerar que no serviço estudado há Unidades em que a estrutura física não permite tal prática. Assim, não se trata de uma opção do profissional, mas, sim, das condições de trabalho disponíveis para a utilização dessa abordagem.

Tendo o referencial do acolhimento fundamentado na escuta ao outro, os cirurgiôes-dentistas descreveram como rotina clínica a pactuação de plano terapêutico compartilhado com os usuários. Para tanto, utilizam como recurso o uso do espelho de mão para o acompanhamento do exame da boca pela pessoa, seguido pela conversa estabelecida durante esse exame.

[...] partimos para o exame clínico, que é negociando com o paciente, eu trabalho muito com o espelho, nas duas cadeiras sempre tem um espelhinho junto, eu pactuo com o paciente que eu vou fazendo o exame e a gente vai conversando (E4).

Em conjunto com o usuário, porque ele é que é o mais importante da relação (E5).

O uso do recurso do espelho de mão para abordagem do usuário já foi descrito em estudos que trataram da aplicação de recursos educativos em saúde bucal com o usuário na clínica odontológica (COUTO et al., 2003; GARCIA et al., 2005). O fato de o usuário se ver durante o exame clínico contribuiu para ampliar sua autonomia de decisóes, além de melhorar o diálogo entre profissional e usuário (BARROS; BOTAZZO, 2011).

Observa-se, assim, uma possibilidade de reconstrução do plano terapêutico entre o profissional e o usuário, em que as decisôes são compartilhadas e repactuadas de acordo com as necessidades percebidas por ambos. É um projeto terapêutico comum com potencial de maior resolutividade.

[...] apresento as possibilidades, converso, e a pessoa é que decide em conjunto, e se naquele momento ela não está disposta ou com outra necessidade, isso também a gente tem que levar em consideração [...] (E3). 
Há de se ressaltar que esse fazer clínico de compartilhamento de decisões conflita com a identidade de constituição profissional do cirurgião-dentista, o qual foi historicamente treinado para ter a autonomia na clínica, que se estabelece como um poder. É o que Freidson (1994) traz como questão central para o entendimento sociológico das profissóes, ou seja, a autonomia e controle que o profissional da saúde tem sobre o seu próprio trabalho. Essa autonomia, representada pelos saberes de cada profissão e suas especificidades, passa a ser desafiada quando se fala em compartilhar decisóes do plano terapêutico com o usuário. Não é um momento simples. Exige do profissional atenção ao ouvir e conseguir perceber as necessidades de saúde de quem busca pelo atendimento odontológico.

Uma ferramenta que apoia e facilita ao cirurgiáo-dentista o acolhimento e diálogo ao usuário é o uso do prontuário de família. O prontuário de família é um recurso adotado nas Unidades de Saúde do SSC/GHC, composto pelos prontuários individuais das pessoas que vivem em um mesmo domicílio. É entendido como um instrumento de trabalho que garante o registro das informaçóes e permite uma melhor comunicação e o diálogo entre as informaçóes registradas pelos profissionais da equipe de saúde (BARROS; BOTAZZO, 2011).

Vemos o que ele [o usuário] precisa, sua história médica, seu vínculo com a Unidade (E1).

A ficha clínica odontológica padrão fornecida pelo serviço que fica no prontuário de família nem sempre é utilizada pelos cirurgiōes-dentistas. Os profissionais que usam parcialmente a ficha clínica odontológica ou não a usam, sentem-se mais livres para realizar a anamnese sem precisar seguir um roteiro preestabelecido, deixando que a pessoa fale sobre a sua vida. Isso faz com que o profissional possa se apropriar de informaçôes essenciais para a constituição de uma boa história clínica, possibilitando uma abordagem mais integral do usuário (registro diário de campo).

Vale ressaltar que as Unidades de Saúde do SSC/GHC são responsáveis pelo cuidado de 108.500 pessoas (IBGE, 2010), sendo que a distribuição da população nos territórios de cada Unidade não é uniforme. O cirurgião-dentista atende, no mínimo, seis consultas programadas por turno, número esse que aumenta de acordo com a Unidade de Saúde e com a demanda de atendimentos de urgência/avaliaçáo do dia.

Desse modo, pode-se afirmar que a análise das rotinas de cuidado dos cirurgiôesdentistas entrevistados indica uma prática voltada para a clínica ampliada em saúde bucal. Uma clínica caracterizada por um acolhimento de escuta ao usuário que 
produz subjetividades e promove a pactuação de um plano terapêutico, no qual as decisóes são compartilhadas e estáo em constante reconstrução, contrário a uma prática essencialmente biológica e centrada na doença do ser humano. Garantir a subjetividade na prática do cuidado é reconhecer um usuário como um sujeito cuja experimentação e interação social - acontecimentos, encontros, vivências múltiplas - são social e historicamente construídas (FRANCO; MERHY, 2011).

Enquanto categoria cultural, as pessoas apresentam diferentes atributos, os quais incluem a racionalidade, autonomia, particularidades de gênero, entre outros (CASTIEL, 2003). Nessa perspectiva, o cuidado em saúde vai exigir a compreensão do sujeito e de seu contexto familiar, social e de mundo (VASCONCELOS; FRATUCCI, 2015). São encontros clínicos que conferem outro sentido à intervenção odontológica, considerando as necessidades de um corpo vivido e de um organismo fisiológico, as quais podem mostrar incompatibilidades quanto às necessidades em saúde percebidas pelo cirurgião-dentista e pelo usuário (BARROS; BOTAZZO, 2011; MERLEAU-PONTY, 2006).

\section{O vínculo usuário-profissional como estratégia de práticas resolutivas do cuidado em saúde}

O vínculo é uma estratégia essencial às práticas de cuidado em saúde no âmbito da APS. É uma tecnologia leve, relacional, que tem contribuído para a mudança do modelo centrado na doença para um modelo centrado no sujeito (PINHEIRO; OLIVEIRA, 2011).

Estabelece-se ao longo de um tempo de contato, independentemente do tipo de problemas de saúde ou mesmo na presença de um problema de saúde (BRASIL, 2007b). Implica uma relação interpessoal de proximidade entre o profissional da saúde e o usuário à medida que se conhecem gradativamente e melhor, permitindo, assim, ampliar o processo de corresponsabilização e autonomia pela saúde, além de carregar um potencial terapêutico (BARATIERI et al., 2012).

Para os cirurgiôes-dentistas desta pesquisa, a clínica foi entendida como um espaço privilegiado para o estabelecimento do vínculo, uma vez que as açôes clínicasambulatoriais são as mais realizadas no trabalho de um cirurgião-dentista na APS (BARROS; BOTAZZO, 2011).

Dada à carga horária que os cirurgiôes-dentistas dedicam ao trabalho em clínica, e considerando todas as atividades em que estão inseridos - preceptoria, vigilância 
dos programas da Unidade de Saúde, atividades coletivas -, o reconhecimento das realidades e histórias de vida dos usuários também se dá no espaço do serviço de saúde. Tal situação pode ser observada tanto em conversas com outros profissionais, como em reunióes de equipe e estudo de casos.

Além dos encontros no espaço da Unidade de Saúde, os espaços externos, como visitas domiciliares, trabalho em áreas de vigilância no território e reuniōes com a população, são momentos de aproximação com o usuário e determinantes para a construção de vínculos.

Isso é possível pelo modelo de atenção à saúde vivenciado na APS, centrado no cuidado das famílias, tendo a presença de uma equipe multiprofissional com o Agente Comunitário de Saúde (MOURA; SILVA, 2015).

Fazendo parte dessa equipe de saúde, o trabalho do cirurgião-dentista na APS é organizado entre o procedimento, a escuta e o reconhecimento da cultura do usuário, aspectos esses que favorecem uma abordagem profissional centrada na pessoa.

[...] a escuta, a compreensão é algo que é importante, a gente deveria ter, exercitar mais, para que as pessoas que sintam acolhidas mesmo, para algo que já não é muito fácil, pois vão mexer na boca, a dor, o estigma, tem um monte de tabu [...] (E3).

No Brasil, observa-se uma aproximação entre as diretrizes presentes nas políticas de saúde e a Abordagem Centrada na Pessoa (ACP). Pela teoria da ACP, a personalidade humana tem uma tendência para o crescimento e a saúde, por meio de atitudes e recursos interventivos que permitem o resgate do potencial realizador existente nos seres humanos, conhecido como a "Tendência Atualizante" e reconhecido como o pilar dessa teoria (BACELLAR et al., 2012).

As atitudes que facilitam essa "Tendência Atualizante" são a empatia (colocar-se no lugar da pessoa para poder compreendê-la e não julgá-la), a aceitação positiva incondicional (receber e aceitar a pessoa como ela é) e a autenticidade ou congruência (capacidade de expressar o que a experiência de estar na relação promove) (GOBBI et al., 2002). Em todo trabalho que envolva as relaçóes humanas, como o trabalho da equipe multiprofissional da APS, a ACP pode ser adotada como forma de lidar com o outro, valorizando a potencialidade terapêutica da relação.

Para ocorrer o vínculo, é necessário que os profissionais de saúde estabeleçam uma relação mais horizontalizada com o usuário, relativizando suas verdades, uma vez que não necessariamente aquilo que tem como valor, terá o mesmo sentido ao usuário.

A questão central é de perceber o outro enquanto sujeito (E7). 
O diálogo com aquele que tem valores muito díspares ao do profissional deve estar pautado na ideia de que aquele que recebe cuidados é tão sujeito que fala, percebe e participa quanto aquele que realiza o cuidado (ILHA et al., 2014). Cabe ao profissional combinar atitudes de tolerância, respeito e compreensão para aceitar o usuário como um ser humano concreto, vivendo em tempo e lugar específicos, sem determinar condiçôes e comportamentos e, ao mesmo tempo, sem que isso signifique aprovação das suas ideias e comportamentos (VILELA et al., 2014). Ao possibilitar a manifestação do usuário e argumentar no intuito de pactuar a melhor decisão de tratamento, o cirurgião-dentista inscreve o elemento vínculo no ato clínico e efetiva a autonomia do sujeito-usuário (SANTOS et al., 2008).

Ao escutar, deve-se dar voz a pessoa, pensar junto com a pessoa [...] essa condiçáo de sujeito traz necessariamente a ideia de que a pessoa vai atuar em conjunto conosco, que não somos nós que vamos trazer uma solução única e mágica, mas que é na produção articulada que a gente vai chegar a uma condição diferente daquela que a pessoa chegou (E8).

Demonstrar interesse pelo usuário, comprometendo-se com suas condiçóes e necessidades, consolida uma relação de vínculo e faz com que o cirurgião-dentista gere nas pessoas a sensação de estarem sendo compreendidas. É um diálogo que torna possível as trocas afetivas e efetivas (SOARES et al., 2013).

A possibilidade de o profissional da saúde assumir a perspectiva do outro no processo de cuidado, caracterizando a empatia na relação, expressa a qualidade da relação entre esses sujeitos (STRECK, 2016; BACELLAR et al., 2012). A confiança no profissional, também mencionada pelos cirurgiōes-dentistas deste estudo como condição de vínculo, permite ao usuário que exponha suas necessidades e questionamentos, tornando possível o diálogo e um cuidado mais abrangente ao longo do tempo (BARATIERI et al., 2012). O fator confiança tem se mostrado efetivo na APS, especialmente quando há presença de doenças e condições crônicas de saúde que demandam mudanças de estilo de vida, adaptaçóes cotidianas e renúncias a hábitos socialmente determinados, como tabagismo, excesso de sal ou açúcar (SALES, 2013).

Esse processo que envolve acolhimento, escuta, empatia e confiança na produção do vínculo só é possível se houver por parte do profissional uma habilidade de se comunicar com esse usuário, conectando-se de maneira genuína às experiências “reais", vividas pelas pessoas (BARROS; BOTAZZO, 2011; GOBBI et al., 2002). 
Outro importante aspecto ressaltado pelos cirurgiōes-dentistas que torna possível a condição de vínculo é a capacidade do profissional de resolver o problema de saúde bucal das pessoas, ou seja,

[...] ser resolutivo na questão clínica, pois a pessoa vem, escuta e conversa, se fazemos uma coisa que não resolve o problema dela, ela também não vai confiar e querer voltar, então precisa ter um retorno da parte clínica, uma melhora (E4).

Uma característica da identidade profissional do cirurgião-dentista é que sua formação se assenta em bases técnicas, portanto, historicamente, a prática odontológica foi construída tendo na prática ambulatorial o seu espaço privilegiado (GONSALVES; OLIVEIRA, 2009). É preciso, no entanto, contextualizar o lugar da técnica no processo do cuidado em saúde. Sem a habilidade técnica há, sem dúvida, o comprometimento da resolutividade em saúde. Essa resolutividade, entretanto, não se reduz ao procedimento concluído tecnicamente com sucesso, mas passa, necessariamente, pela escuta e entendimento do que o outro precisa.

O estabelecimento do vínculo permite que a negociação no encontro clínico caminhe para um consenso de necessidades e responsabilidades. Impede que o ato terapêutico esteja centrado na perspectiva do profissional ou que seja realizado puramente pela manifestação de desejo do usuário. Isso, ao contrário, pode significar um "não vínculo" (SANTOS et al., 2008).

\section{A constituição do cirurgiáo-dentista em ato}

Ao refletirem sobre suas rotinas de cuidado em saúde e percepçóes sobre como estabelecem as relaçôes com os usuários em clínica, as memórias dos entrevistados se voltaram para a formação na graduação, buscando a compreensão sobre como esse trabalhador da APS se constituiu cirurgiāo-dentista.

Os relatos trouxeram marcas de currículos anteriores à implementação das Diretrizes Curriculares Nacionais (DCN), com ênfase em prática clínica "dentária”, pouco conhecimento sobre o funcionamento dos serviços públicos e ausência de inserção e vivências no SUS.

[...] a gente era formado pra ser dentista, e fazer bico no serviço público [...] foi pensar a saúde bucal do ponto de vista da boca. Alguém tem uma boca, tu tem que pensar nos dentes, na boca [...] minha formaçáo em saúde da família foi forjada na prática (E7). 
A educação dos profissionais da saúde, historicamente, seguiu a tendência de currículos fragmentados, centrados nas ciências básicas e nos procedimentos técnicos. Os estudantes, assim, eram responsabilizados pela integração dos conteúdos e se transformavam em objetos aptos a receber informaçôes (FRENK et al., 2010).

$\mathrm{Na}$ odontologia, o ensino e a prática foram marcados pelo uso predominante de tecnologias duras (instrumentos e equipamentos) e leve-duras (conhecimentos estruturados e protocolos), com ênfase na técnica operatória e direcionada para uma prática privatista. Esse contexto, associado à precarização das relaçôes de trabalho, implicou o afastamento dos cirurgióes-dentistas da dimensão subjetiva que toda prática de saúde pressupóe, isto é, do uso das tecnologias leves na produção do cuidado e da assistência num espaço intercessor partilhado nos seus encontros (MERHY, 2007; CARNEIRO NETO et al., 2014).

As mudanças curriculares impulsionadas pelas DCN trouxeram a possibilidade da articulação das instituições de ensino superior à rede assistencial do SUS. A intenção era de formar profissionais comprometidos não apenas com a produção de habilidades técnico-científicas, mas também com a transformação das práticas e da organização do trabalho em saúde (ARAÚJO; ZILBOVICIUS, 2008). Estágios curriculares em cenários de prática do SUS, as diferentes modalidades do PET-Saúde, as disciplinas integradoras e residências multiprofissionais em saúde são exemplos desses avanços (WARMLING et al., 2011; TOASSI et al., 2013; PIZZINATO et al., 2012; FONSÊCA et al., 2014; TOASSI; LEWGOY, 2016; FERREIRA, 2007; DEMARCO, 2011).

Ao analisarem as mudanças ocorridas nos currículos da graduação, os cirurgiôes-dentistas entrevistados, também preceptores do estágio curricular da graduação e da Residência Multiprofissional em Saúde, começam a perceber ganhos na formação desses estudantes relacionados ao entendimento do funcionamento do sistema de saúde, integração e vínculo com a equipe e usuários.

[...] eles começam a entender o funcionamento e começam a conseguir fazer vínculos, seja com a equipe, ou com os pacientes; eles conseguem se integrar com a equipe, e quando vão embora muitos pacientes sentem falta (E11).

O serviço, como espaço pedagógico, não deve ser modificado em sua dinâmica para atender às necessidades do ensino, mas, sim, mostrar-se realmente como está estruturado, propiciando ao estudante contato com a realidade da maneira que ela se apresenta (ARAÚJO; ZILBOVICIUS, 2008; MORITA; HADDAD, 2008). 
Nesse sentido, o preceptor tem um papel fundamental na educação de futuros profissionais, especialmente no que se refere à capacidade de o estudante aprender a aprender com a prática (JESUS; RIBEIRO, 2012).

Independente da trajetória de formação, os cirurgiōes-dentistas participantes desta pesquisa tiveram que passar por processos de mudanças paradigmáticas para atuarem no SUS e guardam uma característica em comum: teceram na prática sua forma de trabalhar na APS. Prática essa que foi sendo aprimorada pelos cursos de pós-graduação realizados e pelas atividades de educação permanente que permeiam o trabalho em saúde na instituição de atuação dos entrevistados. Vivenciar o processo do trabalho vivo, em ato, junto a uma equipe multiprofissional, permitiu que esses cirurgiōes-dentistas se reconhecessem como trabalhadores do SUS. É o espaço das tecnologias leves e que se dá nas relaçôes entre os sujeitos (MERHY, 2007).

O desafio da compreensão de como acontece o cuidado em saúde e as relaçóes de vínculo e empatia com o usuário estão na dimensão subjetiva e micropolítica de cada profissional e na singularidade do trabalho cotidiano, o qual pode ser fortalecido por processos de educaçáo permanente.

Neste estudo, o cirurgião-dentista em ato se constituiu pela interação entre a rotina clínica caracterizada pelo acolhimento e compartilhamento do plano terapêutico e por dispositivos facilitadores do cuidado (apresentar-se e chamar pelo nome, prontuário de família, uso do espelho de mão e abordagem fora da cadeira odontológica). Também, pelas relaçôes de vínculo com o usuário, marcadas pela escuta e comunicação, resolutividade, reconhecimento do contexto de vida, empatia, confiança e ACP, e pelas dimensôes "diálogo, vínculo e subjetividades" na produção do cuidado em saúde, considerando as realidades vividas pelos cirurgiôesdentistas (Figura 1). 
Figura 1. Representação da constituição do cirurgiāo-dentista em ato, na percepção dos profissionais entrevistados.

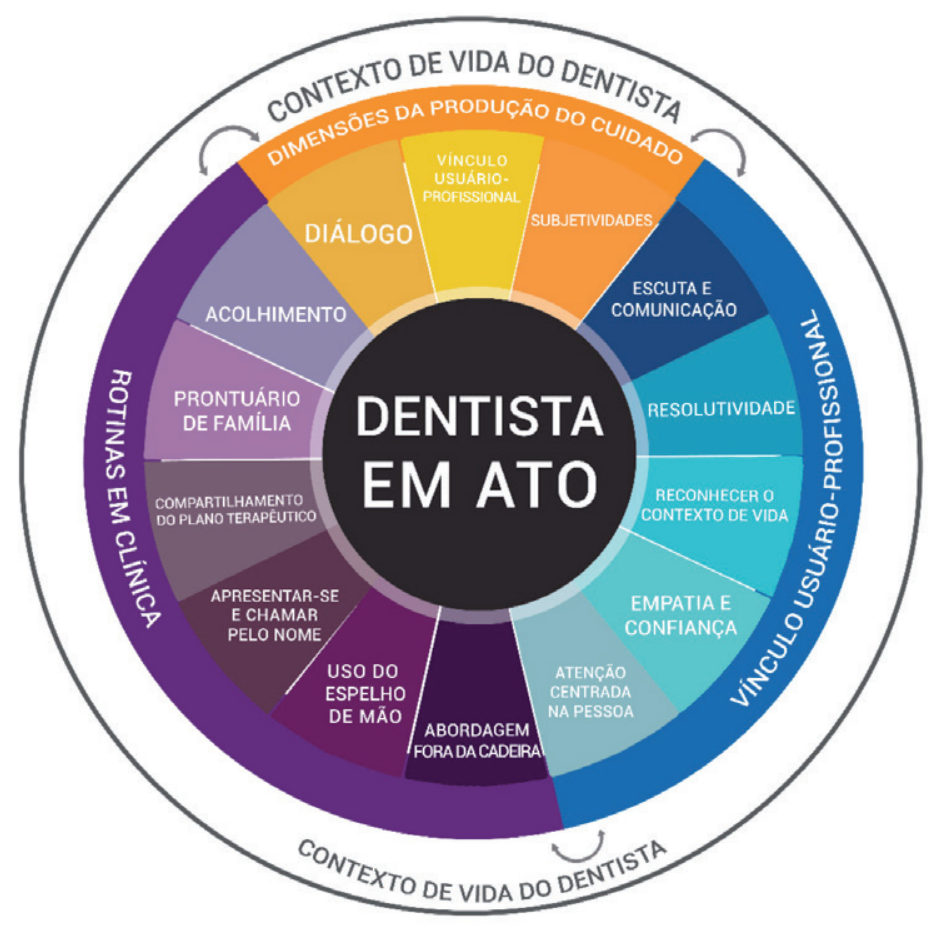

Cabe considerar que a presente pesquisa trouxe a percepção do cirurgião-dentista sobre a produção do cuidado nas práticas clínicas em saúde bucal, um dos sujeitos do encontro terapêutico. Novos estudos, agregando a percepção dos usuários, são recomendados.

\section{Considerações finais}

Os sentidos atribuídos por cirurgiôes-dentistas da APS em relação à produção do cuidado mostraram práticas clínicas caracterizadas por um acolhimento de escuta e diálogo com o usuário, que produz subjetividades e promove a pactuação de um plano terapêutico compartilhado e em constante reconstrução. Trazem a percepção de profissionais com uma compreensão de cuidado contrária a uma assistência com foco essencialmente dentário a partir de necessidades diagnosticadas exclusivamente pelo profissional. A subjetividade se expressou pelo reconhecimento do usuário 
como um sujeito de experimentação e interação social, cujas necessidades do corpo vivido vão além das de um corpo físico.

O contato inicial marcado pela preocupação do profissional em chamar o usuário pelo nome e em apresentar-se, a abordagem fora da cadeira odontológica, bem como a utilização do prontuário de família e do espelho de mão para o acompanhamento do exame da boca pelo usuário, foram dispositivos facilitadores do cuidado na clínica de saúde bucal observados nesta pesquisa.

$\mathrm{O}$ vínculo usuário-profissional estabeleceu-se pela aproximação do cirurgiãodentista com o usuário em encontros no espaço da Unidade de Saúde, mas também em atividades no território que possibilitaram o conhecimento do contexto de vida dessas pessoas. Os cirurgiốes-dentistas apontaram que, para além da formação na graduação e pós-graduação, as suas formas de trabalhar foram tecidas em ato, no trabalho em equipe no cotidiano da APS.

Para que haja a consolidação de propostas de inovação pedagógica no ensino na saúde, como a de novas possibilidades de abordagem clínica na odontologia, bases teóricas articuladas a atividades práticas envolvendo as subjetividades como uma das dimensóes do modo de produção do cuidado em saúde e as tecnologias relacionais devem ser incluídas nos currículos da graduação. O espaço dessas perspectivas teóricas na educação dos profissionais da saúde não se esgota na graduação, mas segue como fundamental na formação de pós-graduação e na educação permanente dos profissionais do SUS. ${ }^{2}$

\section{Referências}

ARAÚJO, M. E.; ZILBOVICIUS, C. A formação acadêmica para o trabalho no Sistema Único de Saúde (SUS). In: MOYSÉS, S. T.; KRIGER, L.; MOYSÉS, S. J. (Coord.). Saúde bucal das familias: trabalhando com evidências. São Paulo: Artes Médicas, 2008, p. 277-290.

AYRES, J. R. C. M. Cuidado e reconstrução das práticas de Saúde. Interface comun. saúde educ. Botucatu, v. 8, n. 14, p. 73-92, set. 2003/fev.2004.

BACELLAR, A.; ROCHA, J. S. X.; FLÔR, M. S. Abordagem centrada na pessoa e políticas públicas de saúde brasileiras do século XXI: uma aproximação possível. Rev. NUFEN. São Paulo, v. 4, n. 1, p. 127-140, jun. 2012.

BARATIERI, T.; MANDU, E. N. T.; MARCON, S. S. Longitudinalidade no trabalho do enfermeiro: relatos da experiência profissional. Rev. esc. enferm. São Paulo: USP, v. 46, n. 5, p. 1260-1267, 2012. 
BARDIN, L. Análise de conteúdo. São Paulo: Edições 70, 2011.

BARROS, R. S.; BOTAZZO, C. Subjetividade e clínica na atenção básica: narrativas, histórias de vida e realidade social. Ciênc. saúde coletiva. Rio de Janeiro, v. 16, n. 11, p. 4337-4348, nov. 2011. BARTOLE, M. C. S. Concepção e formulação de políticas e programas com enfoque da integralidade: o exemplo da Política Nacional de Saúde Bucal. In: LOPES, M. G. M. (Org.). Saúde Bucal Coletiva: implementando ideias... concebendo integralidade. Rio de Janeiro: Rubio, 2008, cap. 11, p. 161-173.

BOTAZZO, C. Sobre a bucalidade: notas para a pesquisa e contribuição ao debate. Ciênc. saúde coletiva. Rio de Janeiro, v. 11, n. 1, p. 7-17, jan./mar. 2006.

. Integralidade da atenção e produção do cuidado: perspectivas teóricas e práticas para a clínica odontológica à luz do conceito de bucalidade. In: LOPES, M. G. M. (Org.). Saúde Bucal Coletiva: implementando ideias... concebendo integralidade. Rio de Janeiro: Rubio, 2008, cap. 1, p. 3-15.

BOTAZZO, C. et al. Inovação na produção do cuidado em saúde bucal. Possibilidades de uma nova abordagem na clínica odontológica para o Sistema Único de Saúde. Relatório Técnico. São Paulo, 2015.

BRASIL. Conselho Nacional de Educação. Câmara de Educação Superior. Resolução CNE/CES 3/2002, de 19 de fevereiro de 2002. Institui as Diretrizes Curriculares Nacionais do Curso de Graduação em Odontologia. Brasília: Diário Oficial da União, 4 de março de 2002. Seção 1, p. 10.

- Ministério da Saúde. Secretaria de Atenção à Saúde. Departamento de Atenção Básica. Coordenação Nacional de Saúde Bucal. Diretrizes da Política Nacional de Saúde Bucal. Brasília, 2004a.

- Ministério da Saúde. Humaniza SUS: Política Nacional de Humanização - a humanização como eixo norteador das práticas de atenção e gestão em todas as instâncias do SUS. Brasília, 2004b.

. Lei 11.129, de 30 de junho de 2005. Brasília: Diário Oficial da União, 1o de julho de 2005. _. Ministério da Saúde. Ministério da Educação. Programa nacional de reorientação da formação profissional em saúde - PRÓ-SAÚDE: objetivos, implementação e desenvolvimento potencial. Brasília, 2007a.

- Conselho Nacional de Secretários de Saúde. Atenção primária e promoção da saúde. Brasília: CONASS, n. 8, p. 41-43, 2007b. (Coleção Pró-gestores - Para entender a gestão do SUS). . Portaria Interministerial no 421. Institui o Programa de Educação pelo Trabalho para a Saúde (PET Saúde) e dá outras providências Brasília: Diário Oficial da União, 3 de março de 2010. . Ministério da Saúde. Secretaria de Atenção à Saúde. Departamento de Atenção Básica. Acolhimento à demanda espontânea. Cadernos de Atenção Básica. Brasília, v. 1, n. 28, 2013. 56p. 
. Ministério da Saúde. Edital no 13 - seleção para o programa de educação pelo trabalho para a saúde PET-Saúde/GraduaSUS - 2016/2017, de 28 de setembro de 2015.

CAMPOS, G. W. S. Equipes de referência e apoio especializado matricial: um ensaio sobre a reorganização do trabalho em saúde. Ciênc. saúde coletiva. Rio de Janeiro, v. 4, n. 2, p. 393403, 1999.

CANALLI, C. S. E. et al. Humanização na relação cirurgião-dentista - paciente. Rev. odontol. Univ. Cid. São Paulo. São Paulo, v. 24, n. 3, p. 220-225, set./dez. 2012.

CARNEIRO NETO, J. L.; CORDEIRO, T. M. S. C.; FALCÃO, M. M. L. Humanização em saúde e a odontologia. Rev. bras. pesqui. Saúde. Vitória, v. 16, n. 2, p. 130-138, abr./jun. 2014.

CASTIEL, L. D. A Palavra - Subjetividade e as coisas - subjetividade. In: GOLDENBERG, P.; MARSIGLIA, R. M. G.; GOMES, M. H. A. (Orgs.). O clássico e o novo: tendências, objetos e abordagens em ciências sociais e saúde. Rio de Janeiro: Editora FIOCRUZ, 2003, cap. 6, p. 95-100.

COUTO, J. L; COUTO, R. S.; DUARTE, C. A. A importância da comunicação na motivação de pacientes. RGO. Porto Alegre, v. 51, n. 5, p. 401-406, nov./dez. 2003.

CUNHA, G. T. A construção da clínica ampliada na atenção básica. 3. ed. São Paulo: Hucitec, 2010.

DEMARCO, E. A. Formação multiprofissional como tecnologia para qualificar a Atenção Primaria à Saúde no SUS: avaliação de um programa de residência. 2011. 83f. Dissertação (Mestrado em Epidemiologia) - Faculdade de Medicina, Universidade Federal do Rio Grande do Sul, Porto Alegre, 2011.

FERREIRA, S. R. Residência Integrada em Saúde: uma modalidade de ensino em serviço. 2007. 117f. Dissertação (Mestrado em Enfermagem) - Escola de Enfermagem, Universidade Federal do Rio Grande do Sul, Porto Alegre, 2007.

FONSÊCA, G. S. et al. Educação pelo trabalho: reorientando a formação de profissionais da saúde. Interface comun. saúde educ. Botucatu, v. 18, n. 50, p. 571-583, 2014.

FONTANELLA, B. J. B. et al. Amostragem em pesquisas qualitativas: proposta de procedimentos para constatar saturação teórica. Cad. saúde pública. Rio de Janeiro, v. 27, n. 2, p. 389-394, fev. 2011.

FRANCO, T. B.; MERHY, E. E. El reconocimiento de la producción subjetiva del cuidado. Salud colectiva. La Plata, v. 7, n. 1, p. 9-20, abr. 2011.

FREIDSON, E. Professionalism reborn: theory, prophecy and policy. Cambridge: Polity Press, 1994.

FRENK, J. et al. Health professionals for a new century: transforming education to strengthen health systems in an interdependent world. J. Lancet. Minneapolis, v. 376, p. 1923-1958, nov. 2010. 
GARCIA, P. P. N. S.; SERRA, M. C.; DOTTA, E. A. V. Primeira consulta: estratégias adotadas por cirurgióes-dentistas para a conquista de pacientes. Rev. odontol. Araraquara: UNESP, v. 34, n. 1, p. 43-48, 2005.

GOBBI, S. L. et al. Vocabulário e noçôes básicas da Abordagem Centrada na Pessoa. 2. ed. São Paulo: Vetor, 2002. 277 p.

GONSALVES, E. M. B.; OLIVEIRA, A. E. O processo de trabalho do cirurgião-dentista na estratégia saúde da família: uma contribuição à construção do SUS. Rev. bras. pesqui. Saúde. Vitória, v. 11, n. 3, p. 44-51, 2009.

GRUPO HOSPITALAR CONCEIÇÃO. Saúde Comunitária. Disponível em: <https://www. ghc.com.br/default.asp?idMenu=unidades\&idSubMenu=5>. Acesso em: 17 jan. 2017.

ILHA, S. et al. Vínculo profissional-usuário em uma equipe da Estratégia Saúde da Família. Ciênc. cuid. Saúde. Maringá, v. 13, n. 3, p. 556-562, jul./set. 2014.

INSTITUTO BRASILEIRO DE GEOGRAFIA E ESTATÍSTICA. Base de informaçôes do censo 2010 por setores censitários. Disponível em: <http://www.censo2010.ibge.gov.br/ sinopseporsetores/>. Acesso em: 26 jun. 2017.

JESUS, J. C. M.; RIBEIRO, V. M. B. Uma avaliação do processo de formação pedagógica de preceptores do internato médico. Rev. bras. educ. méd. Rio de Janeiro, v. 36, n. 2, p. 153-161, 2012. KOVALESKI, D. F.; FREITAS, S. F. T.; BOTAZZO, C. As histórias patográficas como forma de relato de pesquisa de campo. Saúde transfom. soc. Florianópolis, v. 1, n. 1, p. 61-69, 2010.

MATOS, P. E. S.; MENDES, H. J.; SANTANA, M. L. Acolhimento aos usuários do serviço de odontologia de uma universidade pública. Rev. ABENO. Brasília, v. 16, n. 4, p. 85-94, 2016. MATTHEWS, E. Compreender Merleau-Ponty. 2. ed. Rio de Janeiro: Vozes, 2011.

MERHY, E. E. Em busca de ferramentas analisadoras das tecnologias em saúde: a informação e o dia a dia de um serviço, interrogando e gerindo trabalho em saúde. In: MERHY, E. E.; ONOCKO, R. (Orgs.). Agir em saúde: um desafio para o público. São Paulo: Hucitec, 1997, p. 113-150.

. Saúde: a cartografia do trabalho vivo. 3. ed. São Paulo: Hucitec, 2007. 189 p.

MERHY, E. E.; FRANCO, T. B. Por uma composição técnica do trabalho centrada no campo relacional e nas tecnologias leves. Saúde em debate. Rio de Janeiro, v. 27, n. 65, p. 316-323, 2003. MERLEAU-PONTY, M. Fenomenologia da percepção. São Paulo: Martins Fontes, 2006.

MORITA, M. C.; HADDAD, A. E. Interfaces da área da educação e da saúde na perspectiva da formação e do trabalho das equipes de Saúde da Família. In: MOYSÉS, S. T.; KRIGER, L.; MOYSÉS, S. J. (Coord.). Saúde bucal das famílias: trabalhando com evidências. São Paulo: Artes Médicas, 2008, p. 277-290. 
MOURA, R. F. S.; SILVA, C. R. C. Afetividade e seus sentidos no trabalho do Agente Comunitário de Saúde. Physis. Rio de Janeiro, v. 25, n. 3, p. 993-1010, 2015.

NASCIMENTO, A. C. et al. Oral health in the context of primary care in Brazil. Int. dent. $j$. London, v. 63, p. 237-243, 2013.

PINHEIRO, P. M.; OLIVEIRA, L. C. A contribuição do acolhimento e do vínculo na humanização da prática do cirurgião-dentista no Programa Saúde da Família. Interface comun. saúde educ. Botucatu, v. 15, n. 36, p. 187-198, jan./mar. 2011.

PIZZINATO, A. et al. Integração ensino-serviço na formação profissional. Rev. bras. educ. méd. Rio de Janeiro, v. 36, n. 1, supl. 2, p. 170-177, 2012.

PUCCA JÚNIOR, G. A. et al. Oral health policies in Brazil. Braz. oral res. São Paulo, v. 23, n. 1, p. 9-16, 2009.

. Ten years of a national oral health policy in Brazil: innovation, boldness, and numerous challenges. J. dent. res. Washington, v. 94, n. 10, p. 1333-1337, 2015.

SALES, A. L. F. Vinculo como ferramenta de trabalho na atenção primária. 2013. 16f. Trabalho de Conclusão de Residência (Residência Integrada em Saúde - ênfase saúde da família e comunidade) - Escola GHC, Grupo Hospitalar Conceição, Porto Alegre, 2013.

SANTOS, A. M. Organização das açóes em saúde bucal na Estratégia de Saúde da Família: açóes individuais e coletivas baseadas em dispositivos relacionais e instituintes. Rev. APS. Juiz de Fora, v. 9, n. 2, p. 190-200, jul./dez. 2006.

SANTOS, A. M. et al. Vínculo e autonomia na prática de saúde bucal no Programa Saúde da Família. Rev. saúde pública. São Paulo, v. 42, n. 3, p. 464-470, 2008.

SOARES, J. L. et al. Consideraçôes sobre o vínculo em saúde na trajetória de busca por cuidado de idosa e família. Rev. pesqui. cuid. fundam. Rio de Janeiro, v. 5, n. 4, p. 583-590, out./dez. 2013. SOUZA, E. C. F. Bocas, câncer e subjetividades - patografias em análise. 2003. 305f. Tese (Doutorado em Saúde Coletiva) - Faculdade de Ciências Médicas, Universidade Estadual de Campinas, Campinas, 2003.

STRECK, D. R. Metodologias participativas de pesquisa e educação popular: reflexóes sobre critérios de qualidade. Interface comun. saúde educ. Botucatu, v. 20, n. 58, p. 537-547, 2016.

TOASSI, R. F. C.; LEWGOY, A. M. B. Práticas Integradas em Saúde I: uma experiência inovadora de integração intercurricular e interdisciplinar. Interface comun. saúde educ. Botucatu, v. 20, n. 57, p. 449-461, 2016.

TOASSI, R. F. C. et al. Integrated curriculum for teaching dentistry: new directions for training in the field of healthcare. Interface comun. saude educ. Botucatu, v. 16, n. 41, p. 29-42, abr./jun. 2013. 
VASCONCELOS, E. M.; FRATUCCI, M. V. B. Práticas de saúde bucal. UNASUS, 2015. Disponível em: <http://www.unasus.unifesp.br/biblioteca_virtual/esf/2/unidades_conteudos/ unidade15o/unidade15o.pdf>. Acesso em: 26 jun. 2017.

VILELA, S. C.; CARVALHO, A. M. P.; PEDRÃO, L. J. Relação interpessoal como forma de cuidado em enfermagem nas estratégias de saúde da família. Rev. enferm. UERJ. Rio de Janeiro, v. 22, n. 1, p. 96-102, 2014.

WARMLING, C. M. et al. Estágios curriculares no SUS: experiências da Faculdade de Odontologia da UFRGS. Rev. ABENO. Brasília, v. 11, n. 2, p. 63-70, 2011.

\section{Notas}

${ }^{1}$ Trata-se de modalidade de Pós-graduação lato sensu, orientada ao SUS, que oferta formação em serviço para diversas profissóes da área da saúde.

${ }^{2}$ V. A. Graff participou da idealização da pesquisa, construção do referencial teórico, produção e análise dos dados, escrita e revisão final do artigo. R. F. C. Toassi, da idealização e coordenação da pesquisa, construção do referencial teórico, produção e análise dos dados, escrita e revisão final do artigo. 


\section{Abstract}

Oral health clinic as a space for the

production dialogue, connection and

subjectivity among users and dentists of

Primary Care

Qualitative research with a phenomenological basis (case study) whose objective was to analyze the senses attributed to clinical practices of Primary Care (PC) dentists in the care health production. Semistructured interviews guided by a script of guiding questions with dentists who worked in the PC and unstructured observation of clinical routine and records of field diary of these professionals were used for data collection. Sampling was intentional, following the theoretical saturation criteria and density of the textual material produced $(\mathrm{n}=11)$. Results showed dentists with clinical practices capable producing subjectivities and connection characterized by reception of listening and dialogue with the user and by the agreement of a shared therapeutic plan and in constant reconstruction, opposite to a dental-focused assistance, based on necessities diagnosed exclusively by the professional. The user has been recognized as a subject as experimentation and social interaction whose necessities of the lived-body go beyond those of a physical body. Pedagogic innovation proposals in health field curricula should provide theoretical foundation and practical activities that includes subjectivities as one of the dimensions of production mode of the health care and the health relational technologies.

> Keywords: comprehensive health care; dental health; qualitative research; primary care; Unified Health System. 